\title{
Effects of Humic Acid-Irrigation Coupling Techniques on Temperature, Radiation and Rice Growth in Songnen Plain China
}

\section{Ennan Zheng}

Heilongjiang University

\section{Yinhao Zhu}

Heilongjiang University

Jianyu Hu

Heilongjiang University

Tianyu Xu (D1044459115@qq.com)

Heilongjiang University

\section{Zhongxue Zhang}

Northeast Agricultural University

\section{Research Article}

Keywords: agricultural soils, humic acid, fluorescence indexes and leaf chlorophyll, organ fertilizer

Posted Date: January 7th, 2021

DOl: https://doi.org/10.21203/rs.3.rs-139163/v1

License: (c) (1) This work is licensed under a Creative Commons Attribution 4.0 International License. Read Full License 


\section{Effects of Humic Acid-Irrigation Coupling Techniques on Temperature,}

\section{Radiation and Rice Growth in Songnen Plain, China}

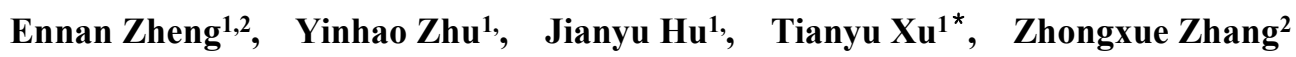

1. School of hydraulic and electric power, Heilongjiang University, Harbin 150080, China

2. Key Laboratory of Effective Utilization of Agricultural Water Resources, Ministry of Agriculture, North east Agricultural University, Harbin 150030, China

* For Corresponding E-mail: 1044459115@qq.com; 2020024@hlju.edu.cn

Abstract: In the past decades, the application of organ fertilizer in agricultural soils has attracted wide attention. However, few studies have carefully explored the effects of humic acid on soil and canopy temperature, radiation, the physiological process of plant leaves, especially coupling with the different irrigation methods. To provide a better growing environment for crops and explore the best regulation mode of humic acid and irrigation coupling techniques in the farmland soil environment in the Songnen Plain Heilongjiang Province, through field experiment, we selected rice as the test crop and applied humic acid in the soil with different irrigation methods. The temperature conditions, radiation, agronomic and fluorescence characteristics were monitored by different stages. The effects of different humic acid and irrigation coupling techniques on the temperature and radiation changes during different growth stages were discussed, and the subtle differences of agronomic and fluorescence characteristics in different growth stages of rice plants were compared. The results showed that the humic acid application with different irrigation methods was not beneficial to the maintenance of soil temperature, the differences among the different treatments, were no found significant at $5 \%$ probability statistically. However, the differences of radiation interception was obvious, and the best value was CT5 treatment, there were also similarities to plant height. The fluorescence indexes and leaf chlorophyll relative content (SPAD) had the differences with the change of humic acid application rate and irrigation methods. Over all, under the humic acid application rate of $1500 \mathrm{~kg} \cdot \mathrm{ha}-1$ with the control irrigation method, could bring the best humic acid and 


\section{irrigation effects.}

\section{Introduction}

In recent 30 years, the rapid and high-intensity development and utilization of land, the large-scale use of chemical fertilizers and pesticides have not only accelerated the degradation of land[1], but also caused the ecological environment pollution $[2,3,4]$, leading to the decline of agricultural product quality and the reduction of production efficiency, Which makes the comprehensive grain production capacity and agricultural sustainable development face severe challenges[5,6,7]. The decline of the quantity and quality of organic matter is the core problem of soil degradation, so ensuring the stability of organic matter in soil is the key to protect land. There is also an important factor to ensure the safety of land, that is the water resources, and the groundwater level is accelerating decline in Songnen Plain China [8.9.10]. Therefore, it is necessary to develop water-saving irrigation in Songnen Plain, to promote water resources and ensure the safety of land.

By reviewing the literature, we found that most of experiments only studied the effects of humic acid on crop and soil environment. For example, Li et al.[11] found that the application of humic acid in the soil could not only optimize the soil structure and increase the utilization rate of fertilizers, but also promote the growth of crops. Meng et al.[12] applied humic acid to the saline-alkali soil, which enhanced salt leaching and inhibit nitrogen losses in the topsoil. The result of Yan et al.[13] and Li [14] showed that soil nutrient contents, yield and quality of crops were increased by application humic acid. Meng et al. [15] showed that because of applying humic acid, the soil microaggregate was increased by $77.59-125.58 \%$. At the same time, 1 salehi et al.[16] considered that the different rates of humic acid improved morphological and biochemical traits in nasturtium flowers. Ren et al. [17] showed that humic acid could reduced the soil $\mathrm{pH}$ and increased the soil organic matter in varying degrees, so that to enhance the growth of rice and increase the yield of rice. Gu [18] and Chen[19] concluded that humic acid could improve soil physical and chemical properties, reduce soil compaction and make soil structure better, 
increase soil fertility, stimulate plant growth and increase plant stress resistance. Liu [20] and Qian et al.[21] found the plant height, stem diameter, ratio of root to shoot, root activity were significantly increased by the addition of humic acid. In summary, few studies about the influences of different humic acid and irrigation coupling techniques on crops, especially in paddy field. Therefore, it is necessary to explore the coupling effects of humic acid and irrigation methods in paddy field. On the basis of these studies, to maintain the soil tillage and the health of the farmland growing environment, our study intends to determine the best regulation mode of humic acid and irrigation coupling techniques for farmland growing environments that is suitable for Songnen Plain through field experiment, to provide a better growing environment for crops.

We selected the humic acid and different irrigation methods for a field rice planting experiment, and we made the following hypothesis: (1) Whether the different humic acid and irrigation coupling techniques could effect the temperature and radiation interception. (2) Appropriate amount of humic acid and irrigation methods would promote rice growth and had a positive impact on agronomic traits. (3) The effects of different humic acid and irrigation methods on the fluorescence of plants were diverse.

\section{Materials and methods}

General description of the experimental area The experiment was performed two years at the National Key Irrigation Experimental Station located on the Songnen Plain at Heping Town, Qing'an County, Suihua, Heilongjiang, China with a geographical location of $45063^{\prime} \mathrm{N}$ and $125 \mathrm{o} 44^{\prime} \mathrm{E}$ at an elevation of $450 \mathrm{~m}$ above sea level (Fig.1). This region consists of plain topography and has a semi-arid cold temperate continental monsoon climate, i.e., a typical cold region with a black glebe distribution area. The average annual temperature is $2.5^{\circ} \mathrm{C}$, the average annual precipitation is $550 \mathrm{~mm}$, the precipitation is concentrated from June to September of each year and the average annual surface evaporation is $750 \mathrm{~mm}$. The growth period of crops is $156-171 \mathrm{~d}$, and there is a frost-free period of approximately 128 days $\mathrm{yr}^{-1}[22]$. 


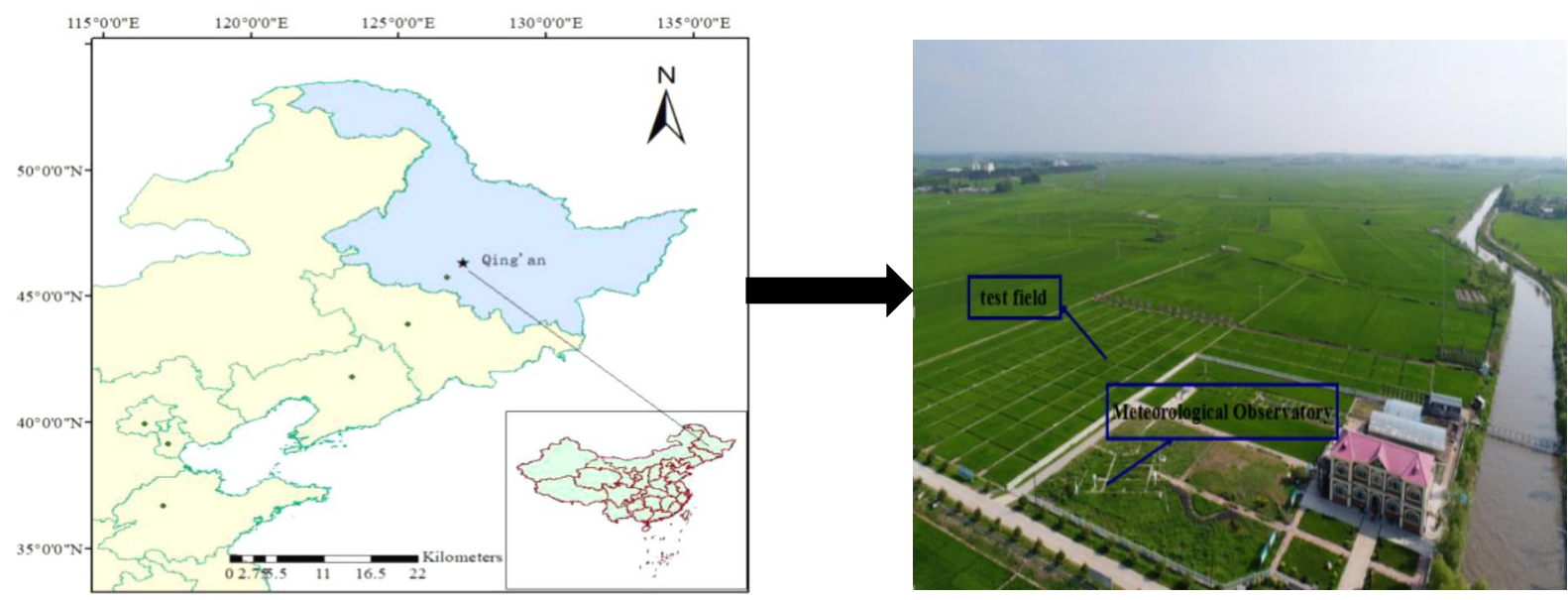

Fig.1. Survey of the study area.

Humic acid The humic acid fertilizer was produced by Yunnan Kunming Grey Environmental Protection Engineering Co., Ltd, China (Fig.2). The organic matter $\geq 61.4 \%$, the moisture $\leq 2.51 \%$, the $\mathrm{pH}$ value was 5.7, the worm egg mortality rate $\geq 95 \%$, and the amount of fecal colibacillosis $\leq 3 \%$. The fertilizer contained numerous elements necessary for plants, such as carbon, hydrogen, oxygen, nitrogen, phosphorus, potassium, calcium, magnesium, sulfur, iron, manganese, zinc, boron, copper, chlorine, molybdenum and silicon. The contents of harmful elements including arsenic, mercury, plumbum, cadmium and chromium were much lower than the test standard.

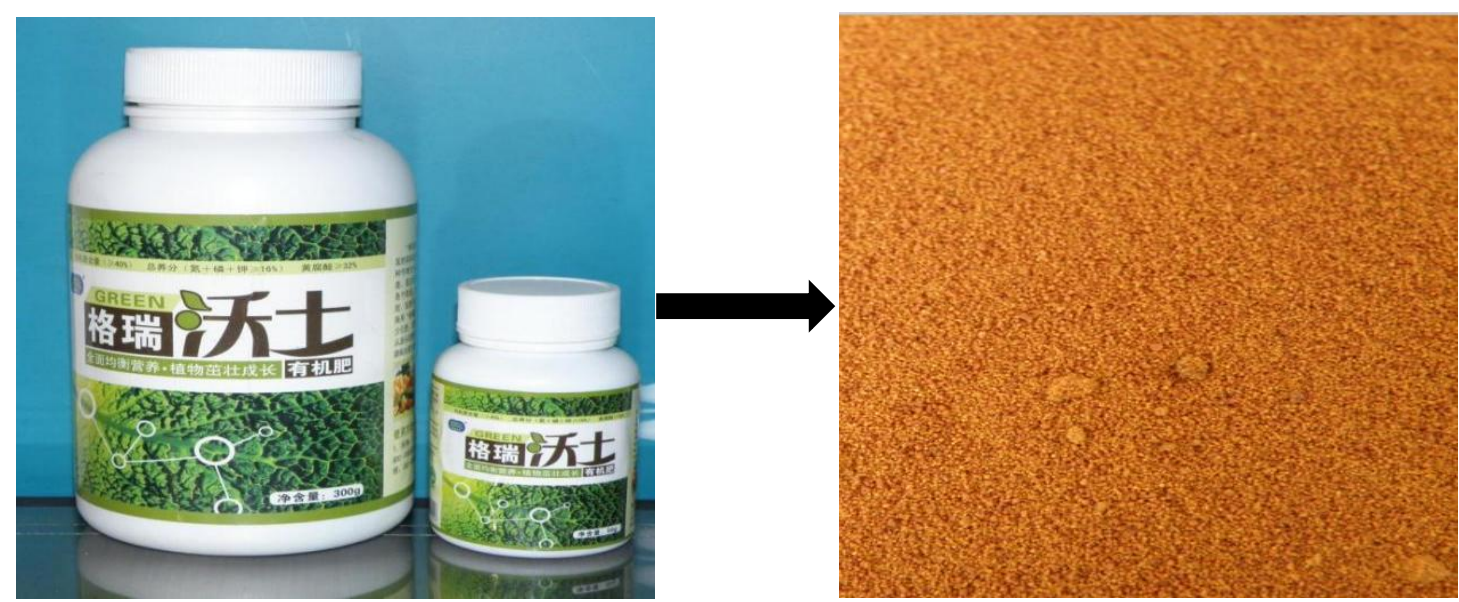

Fig.2. Humic acid fertilizer.

Experimental design and observation methods In this experiment, three irrigation practices, namely: control irrigation (C), wet irrigation (W) and flood irrigation (F) were designed (Table 1). 
Table 1 Different irrigation methods

\begin{tabular}{|c|c|c|c|c|c|c|c|c|}
\hline $\begin{array}{l}\text { Irrigation } \\
\text { practices }\end{array}$ & $\begin{array}{c}\text { Re-green } \\
\text { stage }\end{array}$ & $\begin{array}{c}\text { Early } \\
\text { tillering }\end{array}$ & $\begin{array}{l}\text { Middle } \\
\text { tillering }\end{array}$ & $\begin{array}{l}\text { Later } \\
\text { tillering }\end{array}$ & $\begin{array}{c}\text { Jointing } \\
\text { stage }\end{array}$ & $\begin{array}{c}\text { Heading } \\
\text { stage }\end{array}$ & $\begin{array}{l}\text { Ripening } \\
\text { stage }\end{array}$ & $\begin{array}{l}\text { Yellow } \\
\text { stage }\end{array}$ \\
\hline $\mathrm{C}$ & $0 \sim 30 \mathrm{~mm}$ & $85 \% \theta s \sim \theta s$ & $85 \% \theta s \sim \theta s$ & Field drying & $85 \% \theta s \sim \theta s$ & $85 \% \theta s \sim \theta s$ & $85 \% \theta s \sim \theta s$ & Drainage \\
\hline W & $0 \sim 30 \mathrm{~mm}$ & $0 \sim 30 \mathrm{~mm}$ & $0 \sim 30 \mathrm{~mm}$ & Field drying & $0 \sim 30 \mathrm{~mm}$ & $0 \sim 30 \mathrm{~mm}$ & $0 \sim 30 \mathrm{~mm}$ & Drainage \\
\hline F & $10 \sim 50 \mathrm{~mm}$ & $10 \sim 50 \mathrm{~mm}$ & $10 \sim 30 \mathrm{~mm}$ & Field drying & $10 \sim 50 \mathrm{~mm}$ & $10 \sim 50 \mathrm{~mm}$ & $10 \sim 30 \mathrm{~mm}$ & Drainage \\
\hline
\end{tabular}

Note: $\theta_{s}$ is soil saturated water content, before “ " is the lower limit of irrigation and after " " is the upper limit of irrigation; $\mathrm{C}$ represents control irrigation; W represents wet irrigation; F represents flood irrigation; the numbers represents water layer depth; the percentage represents percent content of soil saturated water content.

Control irrigation (C) of rice had no water layer in the rest of the growing stages, except for the shallow water layer at the re-green stage of rice which was maintained at $0-30 \mathrm{~mm}$ and the natural dryness in the yellow stage[22]. The irrigation time and irrigation quota were determined by the root soil moisture content as the control index. The upper limit of irrigation was the soil saturated moisture content, the lower limit of soil moisture at each growth stage was the percentage of saturated moisture content, and the TPIME-PICO64/32 soil moisture analyzer was used to determine the soil moisture content at 7:00 a.m. and 18:00 p.m., respectively[22,23]. When the soil moisture content was close to or lower than the lower limit of irrigation, artificial irrigation occurred until the upper irrigation limit was reached. The soil moisture content was maintained between the upper irrigation limit and the lower irrigation limit of the corresponding fertility stage. Under the wet irrigation (W) and flood irrigation (F) conditions, it was necessary to read the depth of the water layer through bricks and vertical ruler embedded in the field before and after 8:00 am every day to determine if irrigation was needed. If the irrigation was needed, then recorded the water meter before and after each irrigation. The difference of before and after was the amount of irrigation [23].

In this experiment, Five fertilization treatments were applied: $100 \%$ urea which was $110 \mathrm{~kg} \cdot \mathrm{ha}^{-1}$ (pure nitrogen) (T1), 30\% humic acid and 70\% urea (T2), 50\% humic acid and 50\% urea (T3), 70\% humic acid and $30 \%$ urea (T4), $100 \%$ humic acid which was $1500 \mathrm{~kg} \cdot \mathrm{ha}^{-1}$ (T5). Urea and humic acid were applied according to the proportion of base fertilizer: tillering fertilizer: heading fertilizer (5:3:2). The amount of phosphorus and 
potassium fertilizers were the same for all treatments, $\mathrm{P}_{2} \mathrm{O}_{5}\left(45 \mathrm{~kg} \cdot \mathrm{ha}^{-1}\right)$ and $\mathrm{K}_{2} \mathrm{O}\left(80 \mathrm{~kg} \cdot \mathrm{ha}^{-1}\right)$ were used. Phosphorus was applied once as a basal application. Potassium fertilizer was applied at twice: once as a basal fertilizer and at the 8.5 leaf age (panicle primordium differentiation stage), at a 1:1 ratio [22].

The cultivar "Suijing No.18" was used for the experiment. In first year, on May 21, the rice started to transplant to the field and on May 16 in second year. The crops were harvested on September 20 in first year and September 28 in second year. This study was performed with a randomized complete block design with three replications. The length and width of each plot were $10.0 \mathrm{~m}$ and $10.0 \mathrm{~m}$, respectively $\left(\right.$ area $=100 \mathrm{~m}^{2}$ ). The rice was also planted around the cell as a protection row. A $40 \mathrm{~cm}$ deep plastic plate was embedded between the plots to prevent underground water-fertilizer exchange in each plot. The plant protection and pesticide application measures and field management conditions in each plot were consistent. A soil temperature sensor (HZTJ1-1) was buried in each experimental plot to monitor the temperature of each soil layer $(5 \mathrm{~cm}, 10 \mathrm{~cm}, 15 \mathrm{~cm}, 20 \mathrm{~cm}$ and 25 $\mathrm{cm}$ depth ) and the canopy temperature was measured by the crop canopy temperature measurement system from 08:00 to18:00 o'clock. The transmission of photosynthetically active radiation was measured during 11:00 to 13:00 by using a SunScan Canopy Analysis System (Delta T DevicesLtd., Cambridge, UK), data during the crop growing season were recorded in every day [23].

Plant measurements were taken during the periods of tillering to ripening on days with no wind and good light. The fluorescence parameters were measured by the portable fluorescence measurement system (Li-6400XT, America), the detection light intensity was $1500 \mu \mathrm{mol} \mathrm{m}^{-2} \mathrm{~s}^{-1}$, saturated pulsed light intensity was $7200 \mu \mathrm{molm}{ }^{-2}$ $\mathrm{s}^{-1}$. The functional leaves were dark adaptation, which lasted for $30 \mathrm{~min}$, then the maximum photosynthetic efficiency of PSII $\left(F_{\mathrm{v}} / F_{\mathrm{m}}\right)$ was measured. Photochemical quenching $\left(Q_{\mathrm{P}}\right)$ and non-photochemical quenching $(N P Q)$ were measured with natural light. Simultaneously, the leaf chlorophyll relative content (SPAD) was monitored using SPAD 502 (Konica Minolta, Inc., Tokyo, Japan). For the plant agronomic characteristics, the distance from 
the stem base to stem tip was measured with a straight ruler to quantify plant height [23].

Statistical analysis Experimental data obtained for different parameters were analyzed statistically using the analysis of variance technique as applicable to randomized complete block design. Duncan's Multiple Range Test was employed to assess differences between the treatment means at a 5\% probability level. All statistical analyses were performed using SPSS 22.0 for Windows[24].

\section{Results}

Variation in soil temperature under different humic acid-irrigation coupling techniques In this experiment, the temperature data for the $5 \sim 25 \mathrm{~cm}$ of the soil plow layer were analyzed. The average temperatures of the soil layer during the entire growth period of the plant are shown in (Table 2). Across all treatments, the soil temperature showed the same trend, which was generally divided into two parts. The first part, from $5 \mathrm{~cm}$ to 15 $\mathrm{cm}$, was the soil surface, the soil temperature gradually decreased, the decreased in temperature was approximate $3-4^{\circ} \mathrm{C}$. The second part, from $15 \mathrm{~cm}$ to $25 \mathrm{~cm}$, the soil temperature rose slowly and continued to increase, the increased in temperature was below $1{ }^{\circ} \mathrm{C}$. Under the different humic acid and irrigation coupling techniques conditions, the temperature differences of $15 \mathrm{~cm}$ to $25 \mathrm{~cm}$ were smaller than those $5 \mathrm{~cm}$ to $15 \mathrm{~cm}$. The surface soil temperature $(5 \mathrm{~cm}$ and $10 \mathrm{~cm})$ under the five humic acid application modes, general trend of change showed the order $\mathrm{T} 2>\mathrm{T} 3>\mathrm{T} 1>\mathrm{T} 4>\mathrm{T} 5$, while under the three irrigation conditions the general trend showed the order $\mathrm{C}>\mathrm{W}>\mathrm{F}$. The deep soil temperature $(15 \mathrm{~cm}, 20 \mathrm{~cm}$ and $25 \mathrm{~cm})$, across all treatments, had no significant difference $(P>0.05)$. Based on the above data, among all the different humic acid and irrigation coupling techniques, although there were differences, we had no found significant at $5 \%$ probability statistically $(P>0.05)$, it could be concluded that the humic acid application with different irrigation was not beneficial to the maintenance of soil temperature.

Table 2 The average temperatures of the soil layer during the entire growth in different treatments $\left({ }^{\circ} \mathrm{C}\right)$

\begin{tabular}{ll|c|c|c|c|c|c|c|c|c|c|}
\multicolumn{1}{c}{ First } & year \\
Treatment & Soil layer & $\mathrm{T} 1$ & $\mathrm{~T} 2$ & $\mathrm{~T} 3$ & $\mathrm{~T} 4$ & $\mathrm{~T} 5$ & $\mathrm{~T} 1$ & $\mathrm{~T} 2$ & $\mathrm{~T} 3$ & $\mathrm{~T} 4$ & $\mathrm{~T} 5$ \\
\hline
\end{tabular}




\begin{tabular}{ccccccccccccc}
\hline & $5 \mathrm{~cm}$ & 22.73 & 23.70 & 23.22 & 22.49 & 22.27 & 23.47 & 24.14 & 23.86 & 23.2 & 22.89 \\
& $10 \mathrm{~cm}$ & 21.14 & 22.06 & 21.61 & 20.93 & 20.72 & 22.14 & 22.48 & 22.19 & 21.64 & 21.34 \\
$\mathrm{C}$ & $15 \mathrm{~cm}$ & 19.09 & 19.91 & 19.50 & 18.89 & 18.71 & 19.6 & 20.16 & 19.86 & 19.64 & 19.1 \\
& $20 \mathrm{~cm}$ & 19.61 & 20.45 & 20.03 & 19.41 & 19.21 & 19.95 & 20.54 & 20.72 & 19.74 & 19.46 \\
\hline & $25 \mathrm{~cm}$ & 19.97 & 20.83 & 20.40 & 19.77 & 19.57 & 20.18 & 20.77 & 20.41 & 19.94 & 19.61 \\
\hline & $5 \mathrm{~cm}$ & 22.82 & 22.78 & 22.63 & 22.37 & 21.93 & 22.80 & 23.44 & 23.17 & 22.53 & 22.23 \\
\hline $\mathrm{F}$ & $10 \mathrm{~cm}$ & 21.24 & 21.20 & 21.06 & 20.82 & 20.41 & 21.5 & 21.83 & 21.56 & 21.01 & 20.72 \\
& $15 \mathrm{~cm}$ & 19.19 & 19.16 & 19.00 & 18.80 & 18.42 & 19.03 & 19.58 & 19.28 & 19.07 & 18.54 \\
\hline & $20 \mathrm{~cm}$ & 19.71 & 19.69 & 19.59 & 19.31 & 18.92 & 19.37 & 19.94 & 20.12 & 19.17 & 18.90 \\
& $25 \mathrm{~cm}$ & 20.08 & 20.05 & 19.97 & 19.67 & 19.27 & 19.6 & 20.16 & 19.82 & 19.36 & 19.04 \\
\hline & $5 \mathrm{~cm}$ & 22.73 & 23.48 & 22.93 & 22.43 & 22.10 & 22.98 & 23.56 & 23.24 & 22.76 & 22.39 \\
& $10 \mathrm{~cm}$ & 21.13 & 21.85 & 21.33 & 20.88 & 20.56 & 21.43 & 22.43 & 21.59 & 21.19 & 20.84 \\
\hline W & $15 \mathrm{~cm}$ & 19.14 & 19.73 & 19.25 & 19.85 & 18.56 & 19.16 & 19.6 & 19.27 & 19 & 18.59 \\
& $20 \mathrm{~cm}$ & 19.66 & 20.27 & 19.81 & 19.36 & 19.07 & 19.49 & 19.96 & 19.84 & 19.26 & 18.96 \\
\hline & $25 \mathrm{~cm}$ & 20.03 & 20.64 & 20.19 & 19.72 & 19.42 & 19.70 & 20.18 & 19.89 & 19.48 & 19.15 \\
\hline
\end{tabular}

Note: C represents control irrigation; W represents wet irrigation; F represents flood irrigation; T1,T2,T3,T4,T5 represents five fertilization treatments.

Variation in canopy temperature under different humic acid-irrigation coupling techniques The various in the canopy temperature under the different humic acid and irrigation coupling techniques conditions are shown in Fig.3. The analysis of the difference between canopy temperature and atmosphere temperature showed that the periods of major changes in difference of canopy temperature and atmosphere temperature were all related to atmosphere temperature. When comparing the difference of canopy temperature and atmosphere temperature at the beginning and end of the monitoring period, the average changes in each treatment were small. Under the flood irrigation conditions, no significant changes were found in the difference of canopy and atmosphere temperature with different humic acid application $(P>0.05)$. However, in the observations of the control irrigation and wet irrigation, under T2 treatment conditions, the difference of canopy and atmosphere temperature was below $0^{\circ} \mathrm{C}$, which indicated that these treatments occurred stress effects. In the other treatments, the difference status was more than $0^{\circ} \mathrm{C}$, which indicated that these treatments, water and nutrient were supplied sufficiently, the growth of rice was sustainable and would not change with the actual changes in the growth environment. 

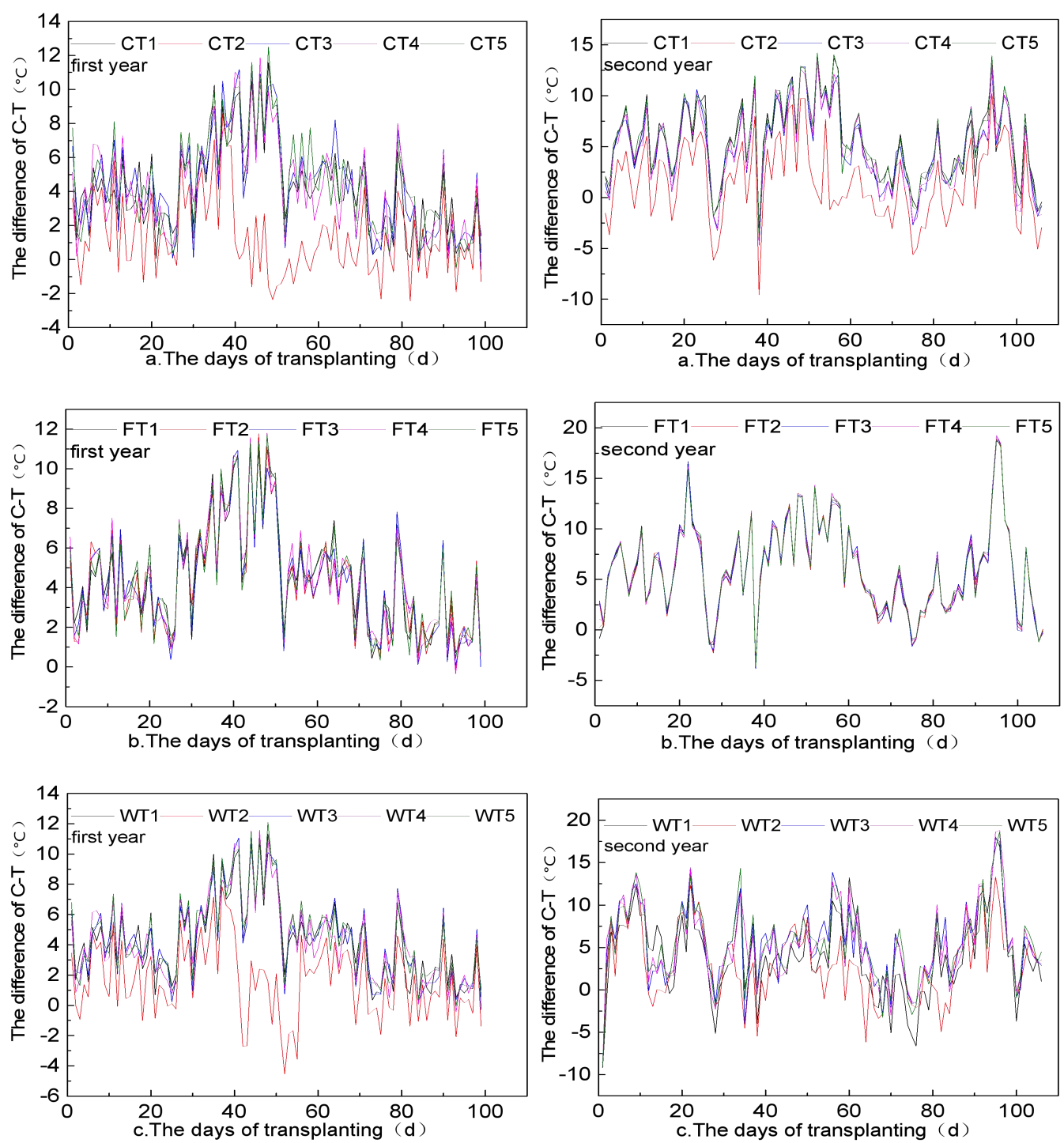

Fig.3 The canopy temperature and atmosphere temperature in different treatments

Note: C represents control irrigation; W represents wet irrigation; F represents flood irrigation; T1,T2,T3,T4,T5 represents five fertilization treatments. respectively. C-T represents the canopy and atmosphere temperature.

Variation in radiation interception under different humic acid-irrigation coupling techniques The variation in radiation interception under the different humic acid and irrigation coupling techniques conditions is shown in Fig.4. Overall, the interception in terms of radiation was mainly completed during three plant growth stages which none-interception stage (0-20days), fast-interception stage (20-70days) and slow-interception stage (70-100days). The change in radiation interception was nonlinear over time, and radiation interception differed under the influence of the different humic acid and irrigation coupling techniques. However, the change trend of radiation interception under the different treatments was synchronous. Under the different humic acid conditions, 
the greatest radiation interception was obtained in T5 treatment, and the minimum value was recorded in $\mathrm{T} 2$ treatment. In addition, the radiation interception under control and flood irrigation was more than wet irrigation. As a whole, in the two years, the experiment showed that when humic acid was applied in the soil $1500 \mathrm{~kg} \cdot \mathrm{ha}^{-1}$ under control irrigation conditions, the values of radiation interception were the maximum, which were 983.3 $\mathrm{MJ} \cdot \mathrm{m}^{-2}$ and $1034.8 \mathrm{MJ} \cdot \mathrm{m}^{-2}$, respectively.
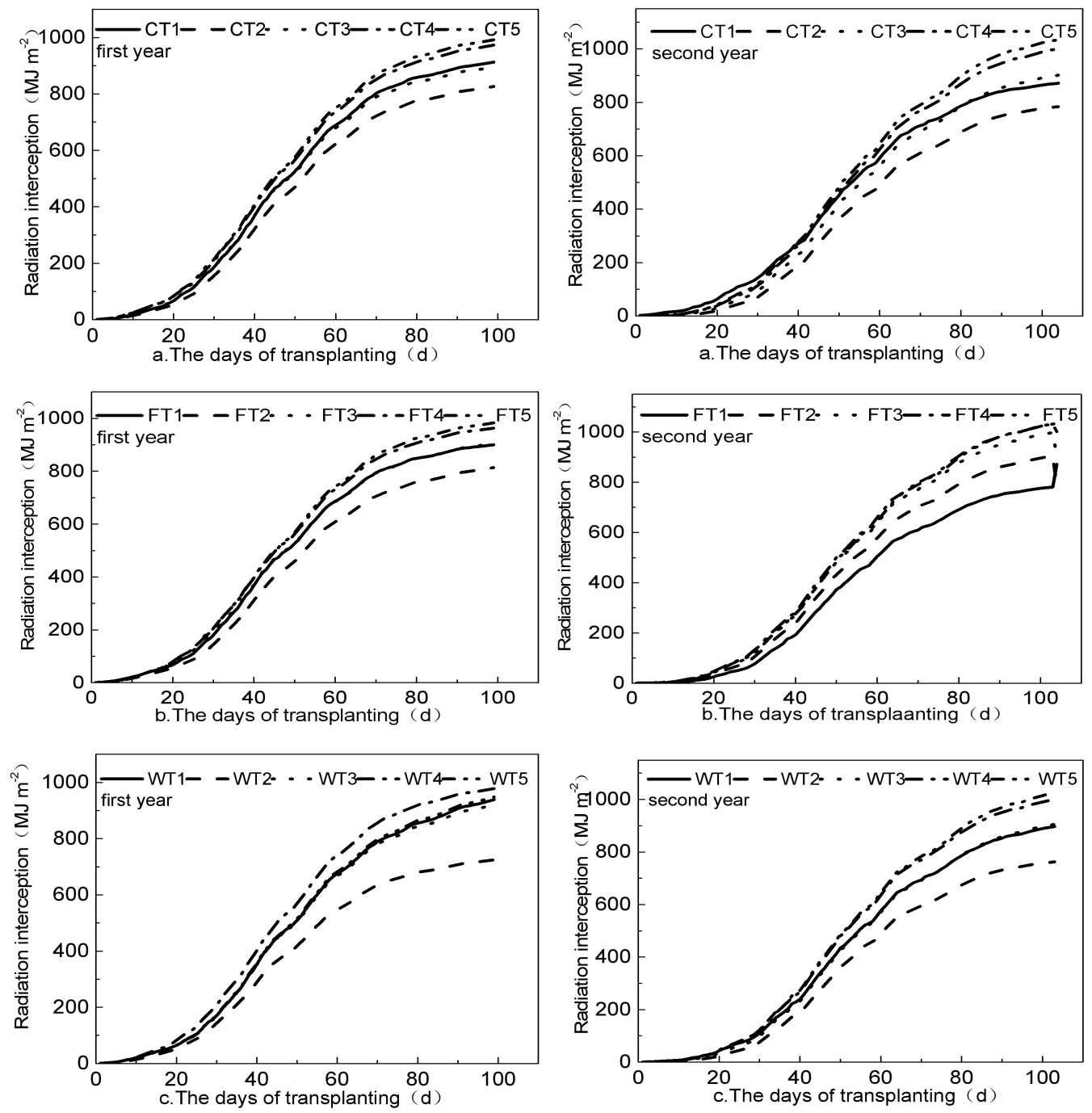

Fig.4 Dynamic change of accumulation interception amount in different treatments

Note: C represents control irrigation; W represents wet irrigation; F represents flood irrigation; T1,T2,T3,T4,T5 represents five fertilization treatments. respectively.

Variation in plant height under different humic acid-irrigation coupling techniques The performance in terms of plant height were similarities to radiation interception, which gradually increased as shown in Fig.5. The 
main growth in plant height occurred during the jointing stage. Across all humic acid and irrigation coupling techniques, the plant height was significantly different at the tillering, jointing and the heading stages. Moreover, there were significant differences among gradients under the different humic acid and irrigation coupling techniques in terms of plant height. According to the results from the tillering stage observation, the plant height in WT2 treatment was the lowest value in the two growth seasons, while that in CT5 treatment had the largest value. In the first growth season, as compared with the other treatments, the plant height in CT5 treatment increased by $7.51 \%(P<0.05), 6.09 \%(P<0.05)$ and $5.45 \%$ on average at the tillering, jointing and heading stage; while in the second growth season, the plant height increased by $9.57 \%(P<0.05), 8.16 \%(P<0.05)$ and $7.48 \%$ $(P<0.05)$, respectively. The increased in plant height of the two growth seasons was significant.
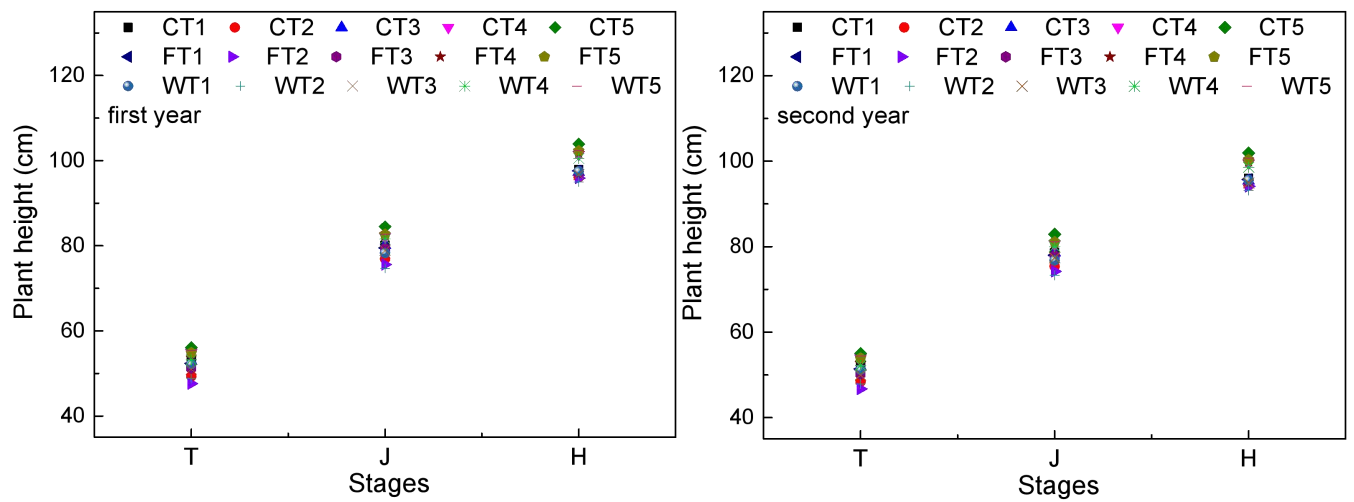

Fig.5 The plant height in different treatments

Note: C represents control irrigation; W represents wet irrigation; F represents flood irrigation; T1,T2,T3,T4,T5 represents five fertilization treatments. T, J, H represents tillering, jointing, heading, respectively.

Rice fluorescence indexes The maximum photosynthetic efficiency of PSII $\left(F_{\mathrm{v}} / F_{\mathrm{m}}\right)$, non-photochemical quenching $(N P Q)$ and photochemical quenching $\left(Q_{\mathrm{P}}\right)$ under different treatments were compared with each other. The differences are shown in Fig.6. In general, the changes in the fluorescence indexes of rice differed under the different humic acid and irrigation coupling techniques, showing a nonlinear change during the entire growth period. Over all, the $F_{\mathrm{v}} / F_{\mathrm{m}}, N P Q$ and $Q_{\mathrm{P}}$ at the jointing and heading stages were higher than those of at tillering and ripening stages in the two years. In our experiment, the main differences of fluorescence indexes were 
occurred at jointing and heading stage, at these stages the $F_{\mathrm{v}} / F_{\mathrm{m}}$ value of CT5, FT5and WT5 was larger than the others, and the best value was recorded in CT5 treatment. And the other treatments, we had no found significant at $5 \%$ probability statistically $(P>0.05)$. The differences of $N P Q$ at these two stags were significant. According to the results from the jointing and heading stages observation, the $N P Q$ in CT5 treatment was significant higher than the other treatments $(P<0.05)$, In the first season, compared with the other treatments, the $N P Q$ in CT5 treatment increased on average by $6.39 \%(P<0.05)$ and $5.94 \%(P<0.05)$ at jointing and heading stage, and increased on average by $6.58 \%(P<0.05)$ and $4.60 \%$ respectively in the second season. As the whole, the $Q_{\mathrm{P}}$ in control irrigation was greater than those of flood and wet irrigation $(P<0.05)$. Moreover, there were no significant differences among gradients under the different humic acid application modes in terms of $Q_{\mathrm{P}}(P>0.05)$. Considering the two factors of irrigation and humic acid, the main factor affected the change of $Q_{\mathrm{P}}$ was irrigation method, the effects of irrigation method was greater than that of humic acid.
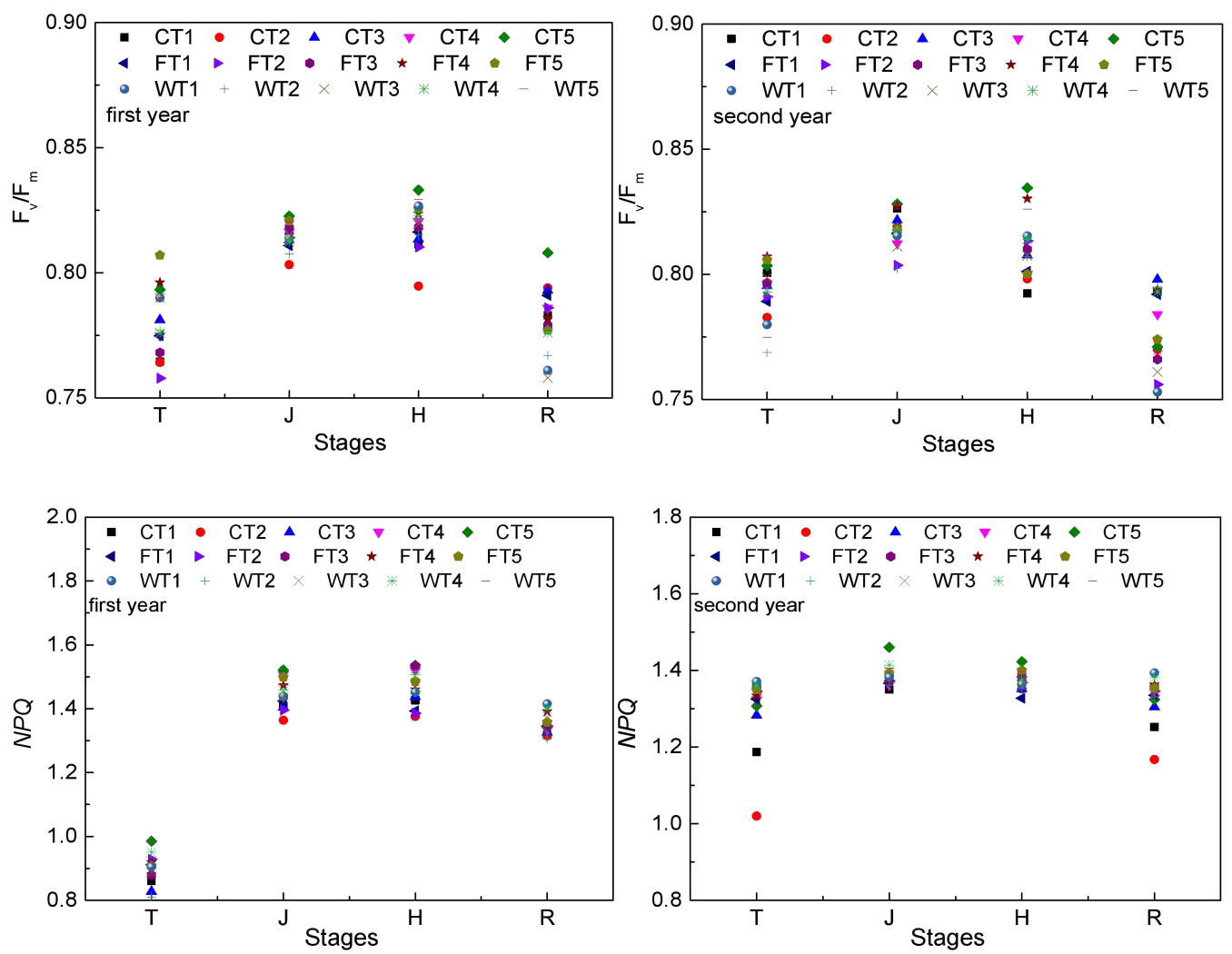

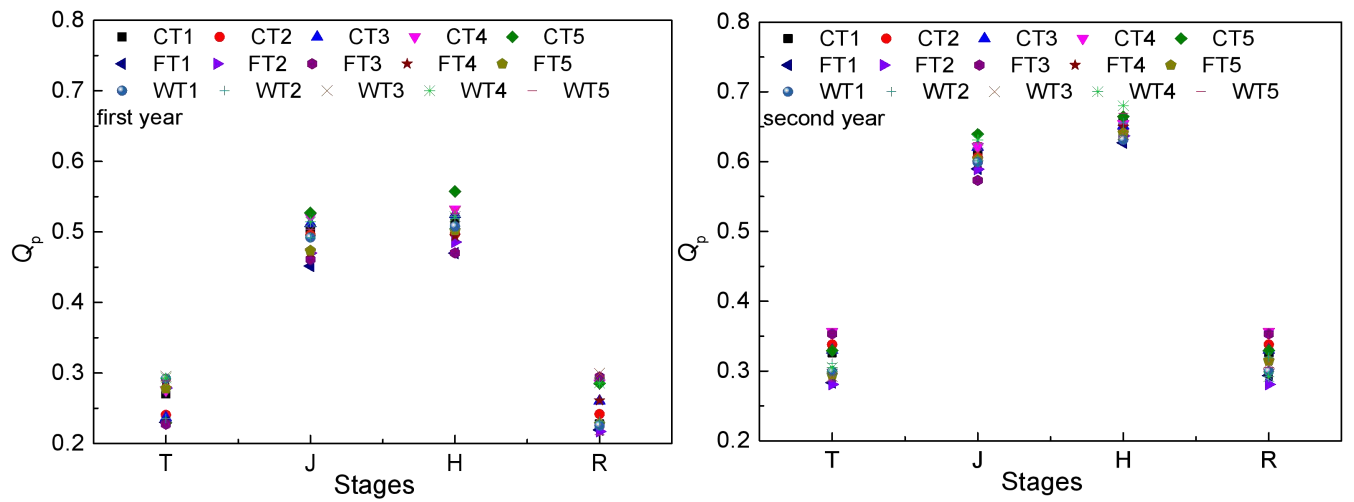

Fig.6 The fluorescence indexes in different treatments

Note: C represents control irrigation; W represents wet irrigation; F represents flood irrigation; T1,T2,T3,T4,T5 represents five fertilization treatments. T, J, H, R, represents tillering, jointing, heading and ripening, respectively.

SPAD The performance in terms of SPAD differed from that of fluorescence indexes, and there were also similarities, as shown in Fig.7. In contrast to fluorescence indexes, the higher SPAD values occurred during the tillering, jointing and heading stages and the growth process was also nonlinear. The order of the SPAD values of the leaves in the different humic acid and irrigation coupling techniques during different growth stages was as follows: jointing stage $>$ tillering stage $>$ heading stage $>$ ripening stage. The results of final measurement showed that the SPAD across all humic acid and irrigation coupling techniques was higher than that in treatment WT2. The SPAD was higher under the CT5 and FT5 treatments, as compared to WT2, at tillering, jointing and heading stages, showing increases of $12.89 \%(P<0.05)$ and $9.10 \%(P<0.05), 11.65 \%(P<0.05)$ and $7.82 \%(P<0.05), 8.43 \%$ $(P<0.05)$ and 5.09\%, respectively in the first season; and $12.92 \%(P<0.05)$ and $11.13 \%(P<0.05), 11.58 \%(P<0.05)$ and $9.61 \%(P<0.05), 8.53 \%(P<0.05)$ and $7.07 \%(P<0.05)$, respectively in the second season. And the higher increases were achieved in CT5 treatment. 

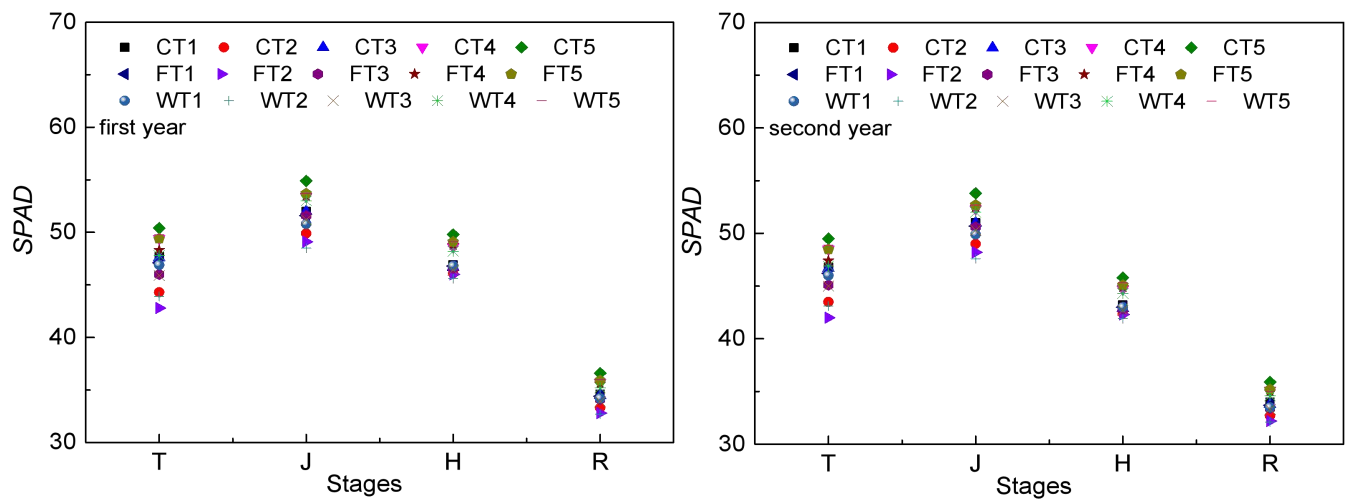

Fig.7 The SPAD in different treatments

Note: C represents control irrigation; W represents wet irrigation; F represents flood irrigation; T1,T2,T3,T4,T5 represents five fertilization treatments. T, J, H, R, represents tillering, jointing, heading and ripening, respectively.

\section{Discussion}

Effect of on the temperature and radiation The different humic acid and irrigation coupling techniques effected the temperature, but not significant. According to the results observation, we found, the main factors of influenced the temperature were the external environments such as atmosphere temperature. As we could see in Fig. 8 , the soil temperature was a significant positive correlation with atmosphere temperature, meanwhile the water layer was also the main factor which effected the soil temperature. Under the control irrigation conditions, there was no water layer in the field, the specific heat capacity of soil was small, absorbs heat quickly, the flood and wet irrigation, due to the existence of water layer, the heat absorption was slow than soil, so the temperature was low than control irrigation. However, due to the different growth status of crops among different humic acid treatments, leaf area index appeared a large difference, which affected the interception of solar radiation, and therefore affected the surface temperature of soil. But, there was no significant difference among different treatments. Because of the differences of the leaf area index, radiation interception also had the significant difference, and in our experiment the CT5 treatment was the higher than the other treatments. The severity of water stress could be reflected by the change of canopy temperature and its time of measurement, providing theoretical support for diagnosing moisture condition of crops quickly. However, the canopy temperature was the average value of different organizations surface the variation of different parts of crops, the change of growth 
conditions and the environment factors would influenced the canopy temperature. Therefore, measurement was needed for a long time and continuous. As given in Fig.3, across all treatments, under WT2 and CT2 conditions, the differences of canopy and atmosphere was below the $0^{\circ} \mathrm{C}$, indicating the water stress occurred. However, among the other treatments, there were no significant difference, the results showed that humic acid and irrigation were not the main factors affecting the of canopy temperature. In Fig.8, we concluded that the atmosphere temperature had a great influence on the canopy temperature both of the two years. The canopy temperature was significant correlation with saturated vapor pressure and relative humidity in second year, however in the first year the correlation had no found significant at $5 \%$ probability statistically. Therefore, the main factors affecting canopy temperature need further study and observation.

Effect of on the rice growth Humic acid is marked as plant biostimulator, which could promote seed germination[25] stimulate plant root growth, and promote the growth of above ground plants [26,27]. Plant height is often regarded as a measure of the photosynthetic and respiratory capacity of plants. Relatively tall plants have more plentiful branches and leaves and thus capture a greater amount of solar radiation[28]. In our experiment, the plant height increased with the increase of humic acid application, and when applying $1500 \mathrm{~kg} \cdot \mathrm{ha}^{-1}$ humic acid, both of the two years, the highest value was recorded in T5 treatment, and among the three irrigation methods, under the control irrigation conditions, the plant height was the larger than that of flood and wet irrigation. Humic acid could be absorbed by plant roots, and the humic acid adsorbed on cell wall could increase the number of proton pumps on plasma membrane, which could promote the output of $\mathrm{H}^{+}$to the cell, acidify the cell wall, hydrolyze the polysaccharide, soften and relax the cell wall, and the cell was easy to elongate and divide, thus promoting plant growth[29]. The growth and development of plants is inseparable from photosynthesis. Chlorophyll and carotenoids are the main pigments of leaf photosynthesis, and they are the basis for plants to absorb, transmit and convert light energy[30]. Studies had shown that humic acid could significantly improve 
SPAD of the pepper[31], wheat [32], maize [33], the results were similar to our experiment. In my study, from the tillering to ripening stages, the highest value of $S P A D$ was in T5 treatment, and under different irrigation conditions, control irrigation was the best. When humic acid coupled the irrigation method was added to the soil, the fluorescence parameters increased significantly, which indicated that the photosynthetic apparatus of leaves was healthy and had good function. Therefore, it had a higher opening degree and excitation energy capture efficiency, at the same time the excitation energy of reaction center increased, so as to promote the formation of plant photosynthetic capacity.
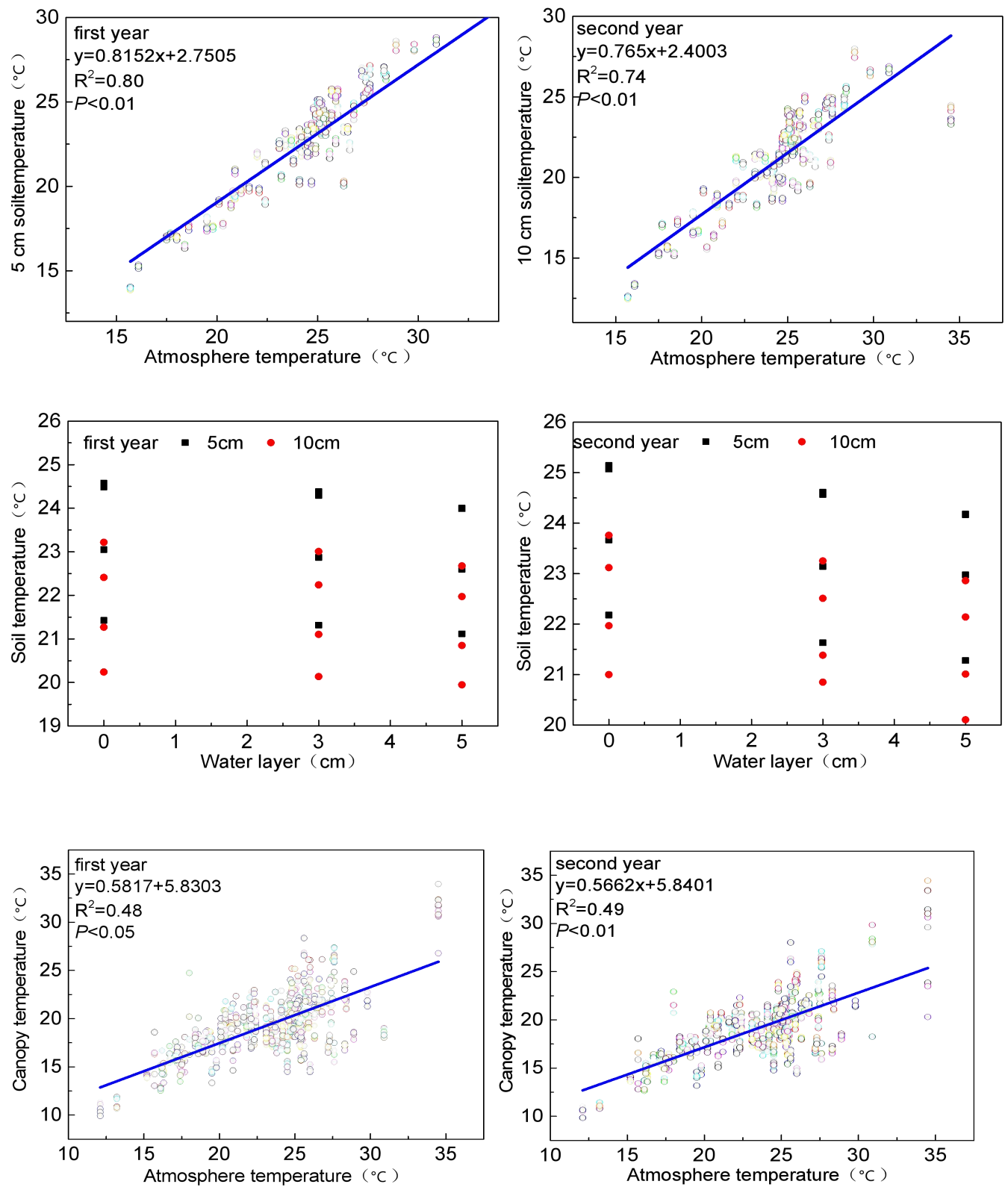

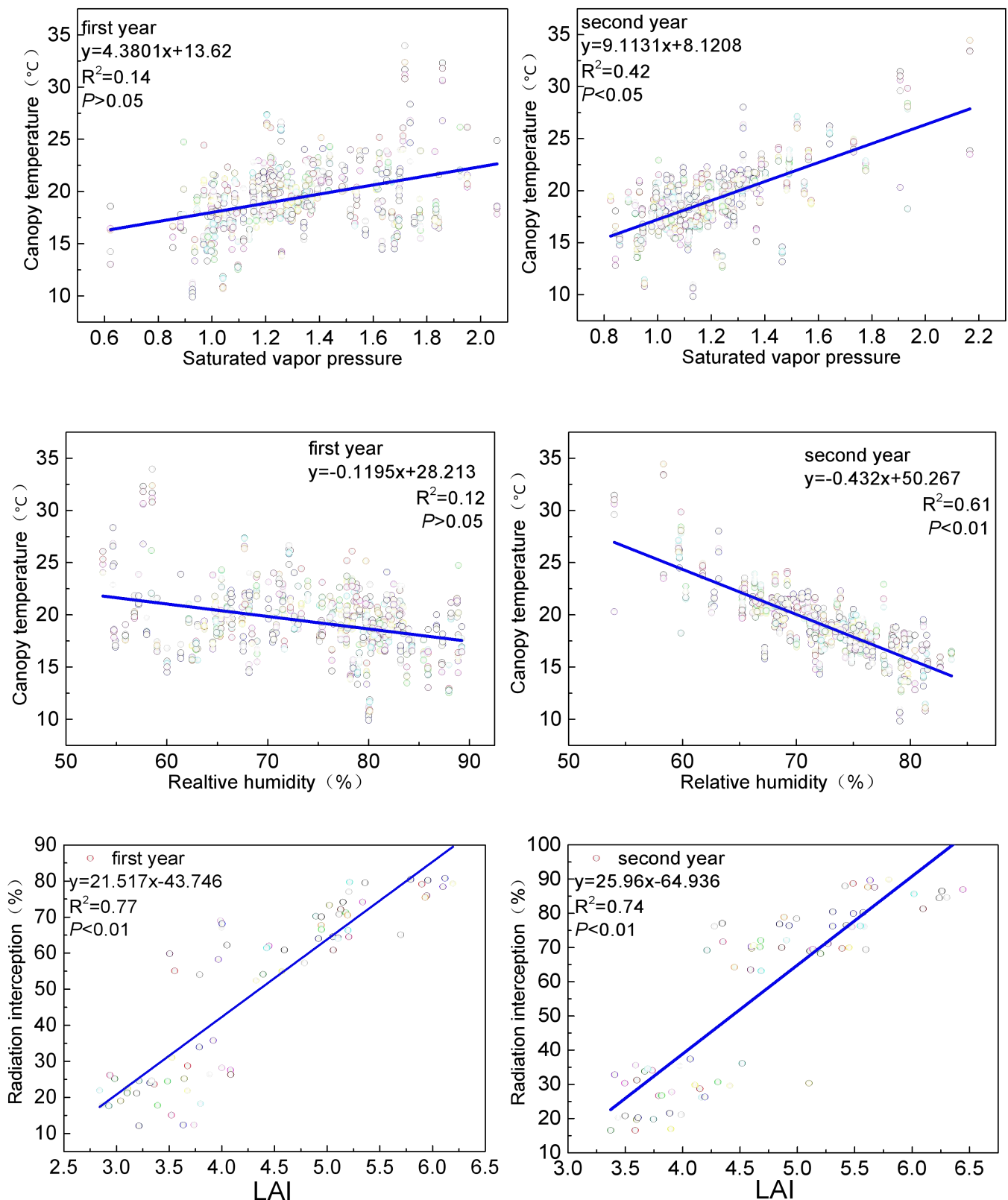

Fig.8 Analysis of influencing factors

Note: $L A I$ represents the leaf index

\section{Conclusion}

During the two years experiment, we found that the different humic acid and irrigation coupling techniques had the a little impacts on the crop growing external environment such as the soil and canopy temperature. When conducting research on vertically distributed of soil temperature, surface temperature was higher. And except for WT2 and CT2 treatments, the differences of canopy and atmosphere were all over the $0^{\circ} \mathrm{C}$, which no significantly different among the other treatments. However, the radiation interception across all treatments, appeared a large 
differences. When application humic acid of $1500 \mathrm{~kg} \cdot \mathrm{ha}^{-1}$ under control irrigation conditions (CT5 treatment), the radiation interception was the largest. Compared the external environment, the different humic acid and irrigation coupling techniques had the a large impacts on the crop agronomic and fluorescence indexes of rice. According to the results of the two-year tests, the application of humic acid significantly effected the plant height, and were similarities to the fluorescence and SPAD indexes. And in CT5 treatment had the better humic acid and irrigation coupling effects.

\section{Data availability}

The data that support the findings of this study are available from the corresponding author on reasonable request.

\section{Reference}

1.Han, X Z., Zou., W X. Effects and suggestions of black soil protection and soil fertility increase in northeast China. Bulletin of Chinese Academy of Sciences, 33 (2) : 206-212(2018).

2.Zou, W X., Qiu, C., Han, X Z. Effects of long-term manure application on black soil fertility and maize yield. Soils and Crops, 9(4) : 407-418(2020).

3.Du, W Y., Tang, S., Wang, H. The status of organic fertilizer industry and organic fertilizer resources in China. China soil and fertilizer, (3):210-219(2020).

4.Li, H Q., Yao, Y F., Zhang, X J., Zhu H S., Wei X R. Changes in soil physical and hydraulic properties following the conversion of forest to cropland in the black soil region of Northeast China. Catena, (prepublish)(2020).

5.Gao, Y., Zhang, Y., Zhang, C., Chen, X W., Liang, A Z. Interactive effects of tillage practices and cropping systems on the interannual variation of soil carbon, nitrogen content and corn yield in Mollisols. Soils and Crops,9(04):323-334(2020).

6.Zhang, X Y., Sui, Y Y., Zhang, X D. Spatial variability of nutrient properties in black soil of Northeast China. Pedosphere, 17( 1) : 19-29(2017). 
7.Wang, F., Han, X Z., Li H B. Hydro-physical properties of black soil in different type of eco-system.Journal of soil and water conservation, 20 ( 6) : $67-70(2006)$.

8.Wang, Q R., Mei, X R. Strategies for sustainable use of agricultural water resources in China.Journal of Agriculture, 7(10):80-83(2017).

9.Lu, H N., Kang, S Z., Du, T S. Current status and future research trend on water-saving high-efficiency and eco-friendly agriculture. Journal of Agriculture ,8(1):155-162(2018).

10.Wang, X L., Wang, Y., Cao, H., Zhamg, W W. Effects of humic acid seed-coating on seed germination and seedling growth of maize in water stress. Maize science, 18(4): 96-98(2010).

11.Li ,Y N. Research Progress of Humic Acid Fertilizer on the Soil. Journal of Physics: Conference

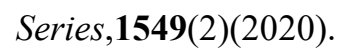

12.Meng, L L., Chong, W., Xue, L L., Yu, C L., Yi, F W. Saline-alkali soil applied with vermicompost and humic acid fertilizer improved macroaggregate microstructure to enhance salt leaching and inhibit nitrogen losses. Applied Soil Ecology,156 (prepublish)(2020).

13.Yan, L., Feng, F., Jian, L W., Xiao, B W., Rong, Z C., Guo, S L., Fu, L Z., De, S H Humic Acid Fertilizer Improved Soil Properties and Soil Microbial Diversity of Continuous Cropping Peanut: A Three-Year Experiment. Scientific Reports, 9(10)(2019).

14.Li, Y N. The explore of humic acid fertilizer application in soil. South China agriculture,13(29):184-185(2019).

15.Meng, L L., Chong, W., Fu, Y W., Yong, J X. Maize (Zea mays) growth and nutrient uptake following integrated improvement of vermicompost and humic acid fertilizer on coastal saline soil. Applied Soil Ecology, 142:147-154(2019).

16.lsalehi, m., Chehrazi2, Sasan, M. The Effect of Nano Calcium and Potassium humic acid Fertilizer on 
Morphological and Biochemical Traits of Nasturtium Tropaeolum majus. Journal of Agricultural Science and Sustainable Production,27(4)(2017).

17.Ren, Z X., Li, S S., Qin, Y L. Effects study of biological humic acid fertilizers with different ratios on the growth of Jingxi Rice. Humic acid,(02):37-41(2019).

18.Gu, D Y. Effects of humic acid on cucumber (Cucumis sativus L.) physiological metabolism under nitrogen stress. Shandong Agricultural University(2016).

19.Chen, S G. Development of humic acid soil conditioner and application on acidizing orchard soil. Shandong Agricultural University (2019).

20.Liu, M. Study on application of humic acid in plug seeding production of tomato and cucumber. Shandong Agricultural University(2016).

21.Qin, X., Yin, Y A., Jia, S J., Chen, Y F., Zhao, S L., Liu, X W., Li, L. Effects of application of potassium humate on the growth and yield of rice under film- mulched drip irrigation conditions. Barley and cereal sciences,36(06):26-28(2019).

22.Zheng, E N., Yang, H., Zhang, Z X. Influence of different nitrogen forms application on rice photosynthesis: fluorescence with water-saving irrigation in black soil region of Songnen Plain, Northeast China. Paddy and water environment, 16(04):795-804(2018).

23.Zheng, E N., Zhang, C., Qi, Z J. Canopy Temperature Response to the Paddy Water Content and Its Relationship with Fluorescence Parameters and Dry Biomass. Agricultural research, 9, 599-608(2020).

24.Zheng, E N., Chao, Z ., Zhi, J Q., Zhong, X Z. Experimental Study on Radiation utilization Efficiency and Soil Temperature in Paddy Field with Different Irrigation Methods in Northeast China. Paddy and water environment, 17(04)(2019).

25.Wang, B., Huang, Y., Sun, Y L., Yu, Y M. Experimental study on the coupling effect of water and nitrogen in 
rice at the high latitudes in cold regions. Hydro science and cold zone engineering, 3(04):47-51(2020).

26.Li, X H., Yin, W Y., Zou, L M., Zheng, P., Li, S M. Preliminary investigation of physiological and biochemical mechanisms on drought resistance of water enhanced by leaf spraying fulvic acid. Chines Bulletin of Botany, 9(2): 44-46(1992).

27.Hagag, L F., Shahin, M F. Effect of NPK and humic substance applications on vegetative growth of egazy olive seedlings. American-Eurasian. Agricultural and environment science.11 (6): 807-811(2011).

28.Mexal, J G., Landis, T D. Target seedling concepts: height and diameter. In: Rose, R., Campbell, S.J., Landis, T.D. (Eds.), Target Seedling Symposium: Proceedings of the Western Forest Nursery Associations. USDA Forest Service Gen. Tech. Rep. RM-200, pp. 17-36(1990).

29.Hager, A., Debus, G., Edel, H G. Auxin induces exocytosis and the rapid synthesis of a high turnover pool of plasma-membrane $\mathrm{H}^{+}$-ATPase. Planta, 185(4): 527-537(1991).

30.Ge, Y., Wang, T., Wang, N., Wang, Z., Liang, C., Ramchiary, N., Choi, S R., Lim, Y P., Piao, Z Y. Genetic mapping and localization of quantitative trait loci for chlorophyll content in Chinese cabbage. Scientia horticultural,147: 42-48(2012).

31.Sun, Z M., Xue, S C., Liang, W J., Liu, Y Z. Effects of different application rates of humic acid compound fertilizer on pepper and its mechanism of anti-se-nility and incremental yield. Chinese journal of applied ecology, 15(1): 81-84(2004).

32.Liang, T P., Wang, Z L., Liu, J., Chen, X G., Shi, C Y. Effect of humate compound fertilizer on physiological characteristics and yield of wheat under irrigated and rain-fed conditions. Chinese journal of eco-agriculture, 17(5): 900-904(2009).

33.Anjum, S A., Wang, L., Farooq, M. Fulvic acid application improves the maize performance under well-watered and drought conditions. Journal of agronomy and crop science, 197(6): 409-417(2017). 


\section{Acknowledgement}

This work was jointly supported by Basic Scientific Research Fund of Heilongjiang Provincial Universities (2020-KYYWF-1042) and the National Natural Science Foundation of China (51809042, 51779046). We are grateful to the staff of the National Key Irrigation Experimental Station for their technical assistance.

\section{Author contributions}

XTY has contributed most to the conception, guidance, and revising of the manuscript. The data acquisition and analysis were done by ZEN and ZZX. The manuscript was written by ZEN, and ZYH and HJY were drawn the Figs. All authors read and approved the final manuscript.

\section{Competing interests}

The authors declare that they have no competing interests.

Additional information

Correspondence and requests for materials should be addressed to XTY

Reprints and permissions information is available at www.nature.com/reprints.

Publisher's note Springer Nature remains neutral with regard to jurisdictional claims in published maps and institutional affiliations. 


\section{Figures}

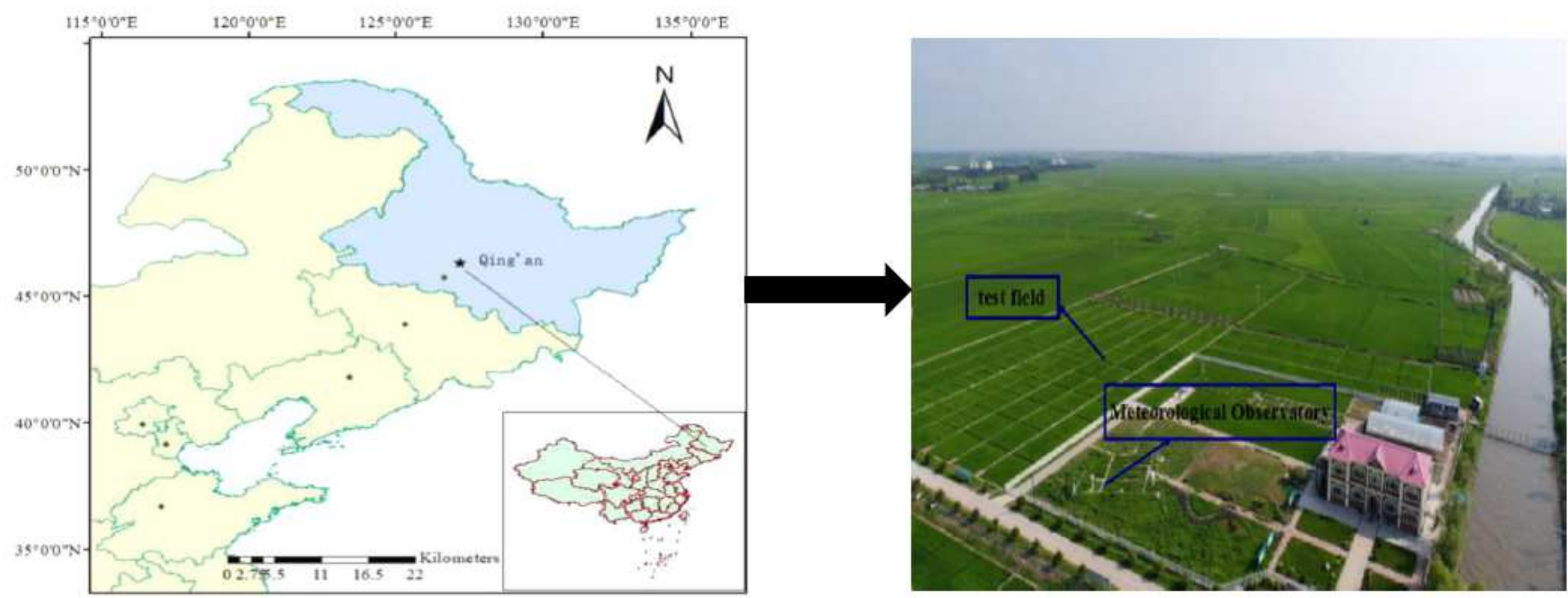

\section{Figure 1}

Survey of the study area. Note: The designations employed and the presentation of the material on this map do not imply the expression of any opinion whatsoever on the part of Research Square concerning the legal status of any country, territory, city or area or of its authorities, or concerning the delimitation of its frontiers or boundaries. This map has been provided by the authors.
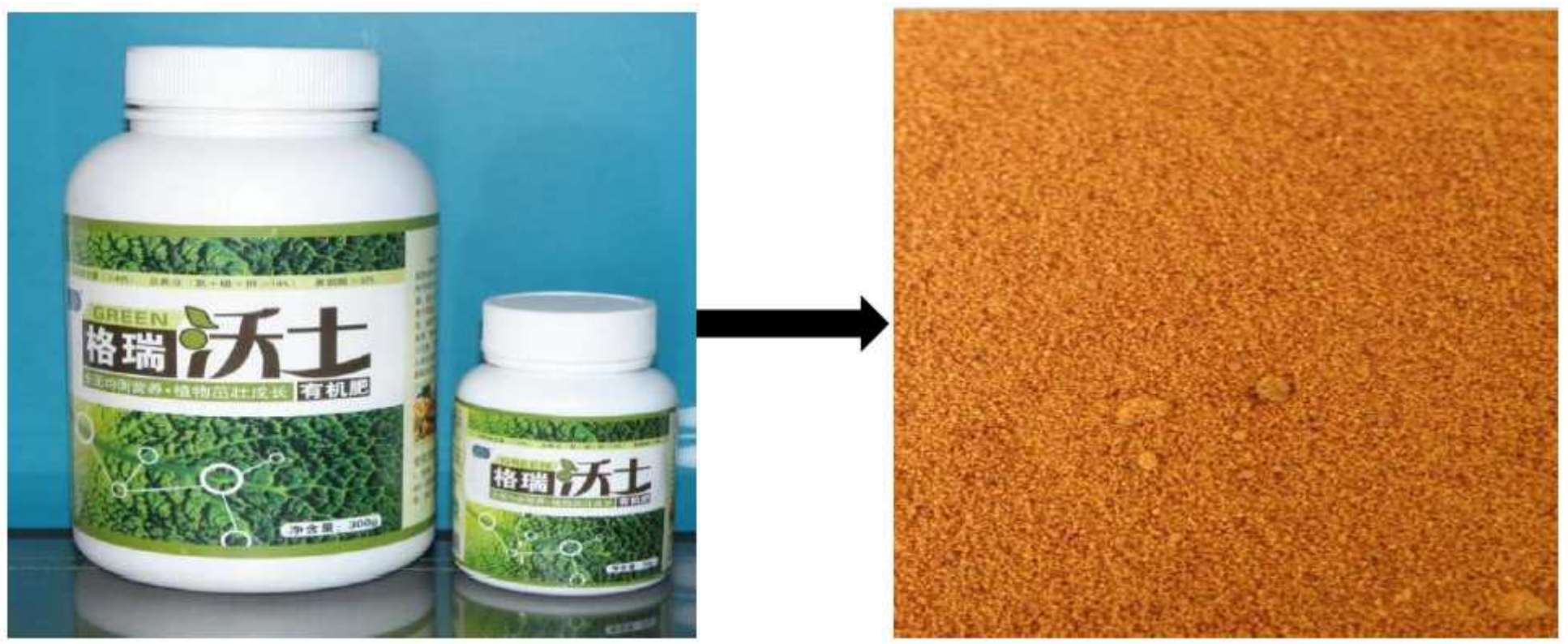

\section{Figure 2}

Humic acid fertilizer. 

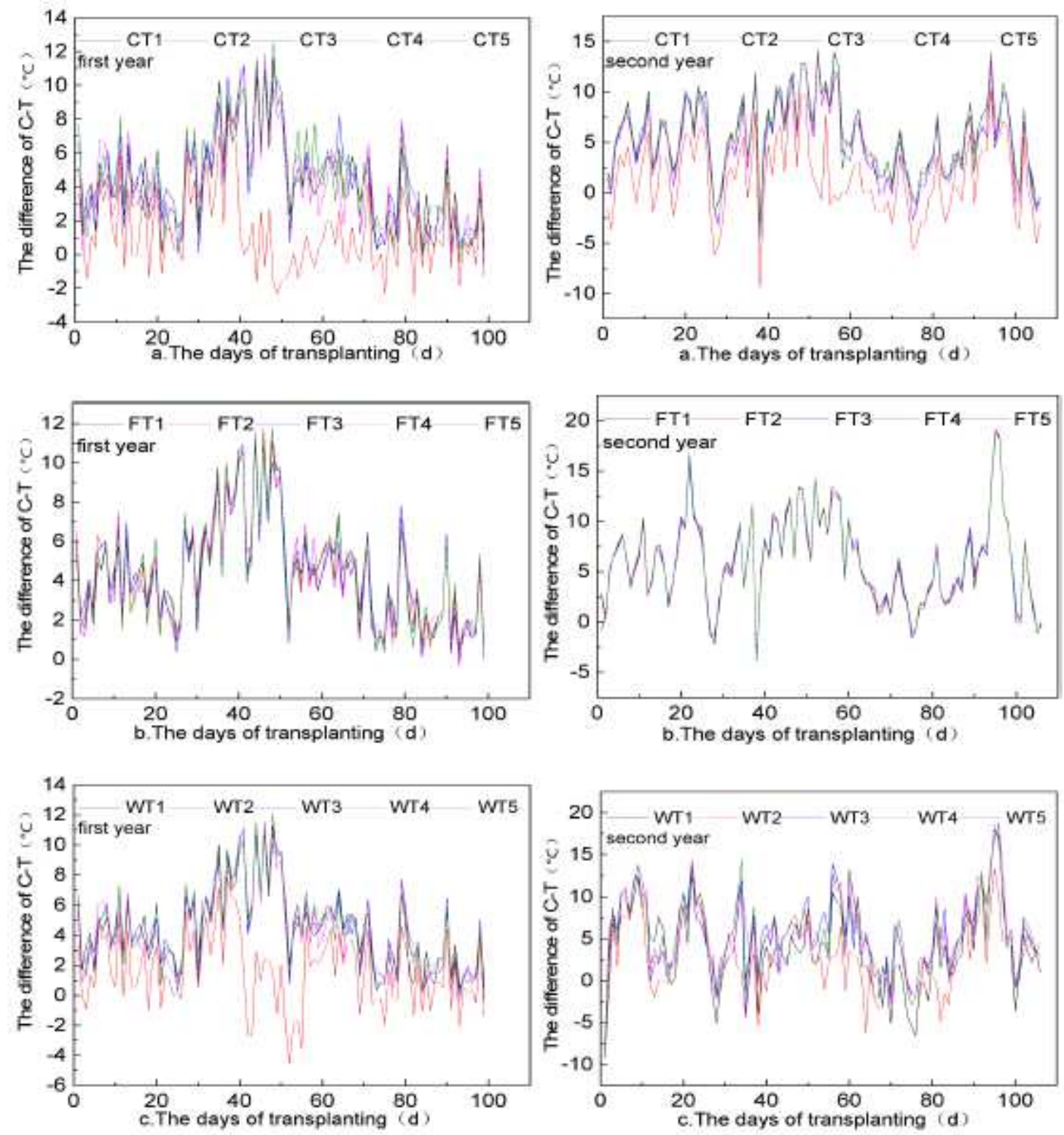

Figure 3

The canopy temperature and atmosphere temperature in different treatments Note: $C$ represents control irrigation; $W$ represents wet irrigation; $F$ represents flood irrigation; $T 1, T 2, T 3, T 4, T 5$ represents five fertilization treatments. respectively. C-T represents the canopy and atmosphere temperature. 

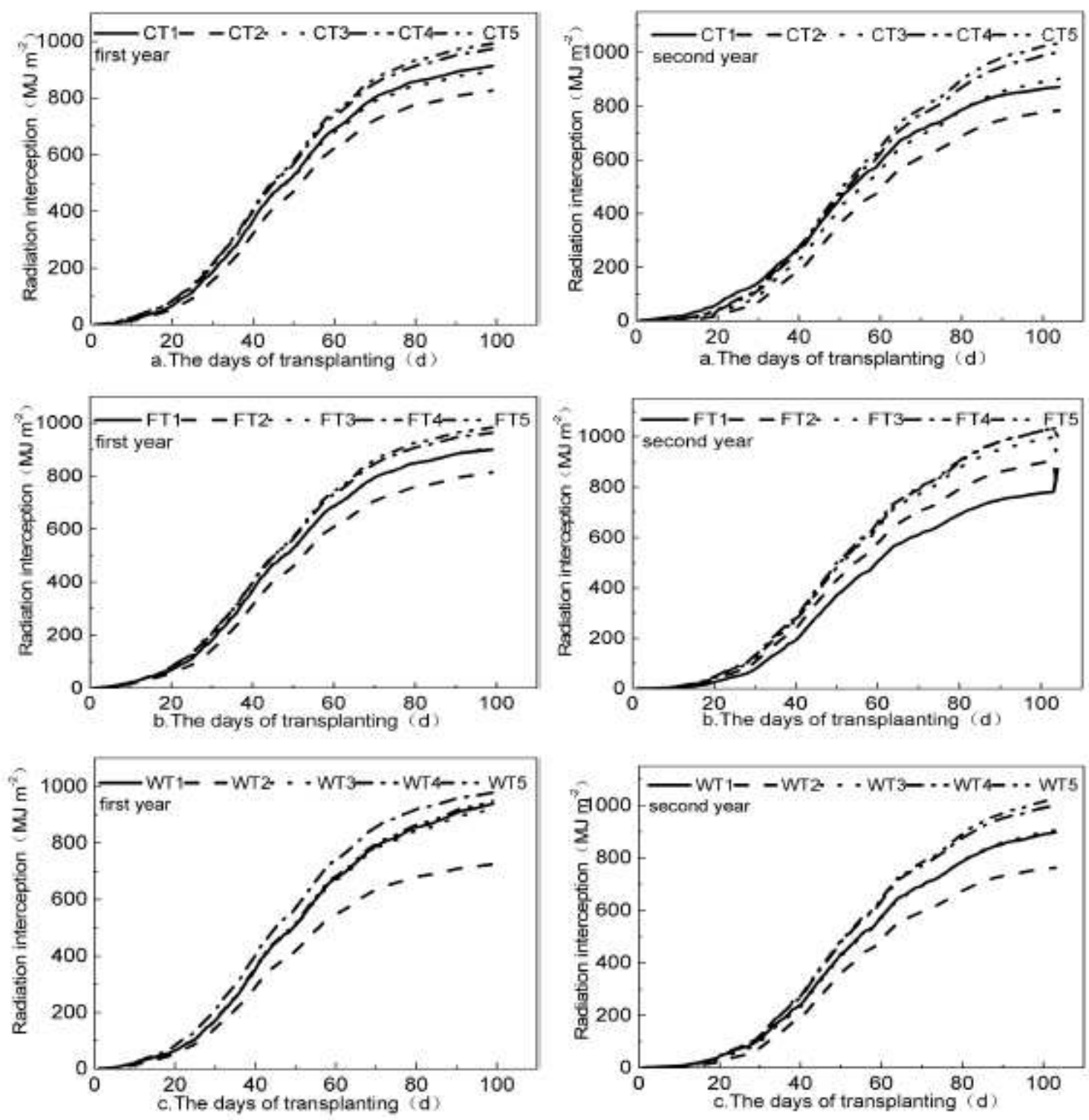

\section{Figure 4}

Dynamic change of accumulation interception amount in different treatments Note: $\mathrm{C}$ represents control irrigation; $W$ represents wet irrigation; $F$ represents flood irrigation; $T 1, T 2, T 3, T 4, T 5$ represents five fertilization treatments. respectively. 

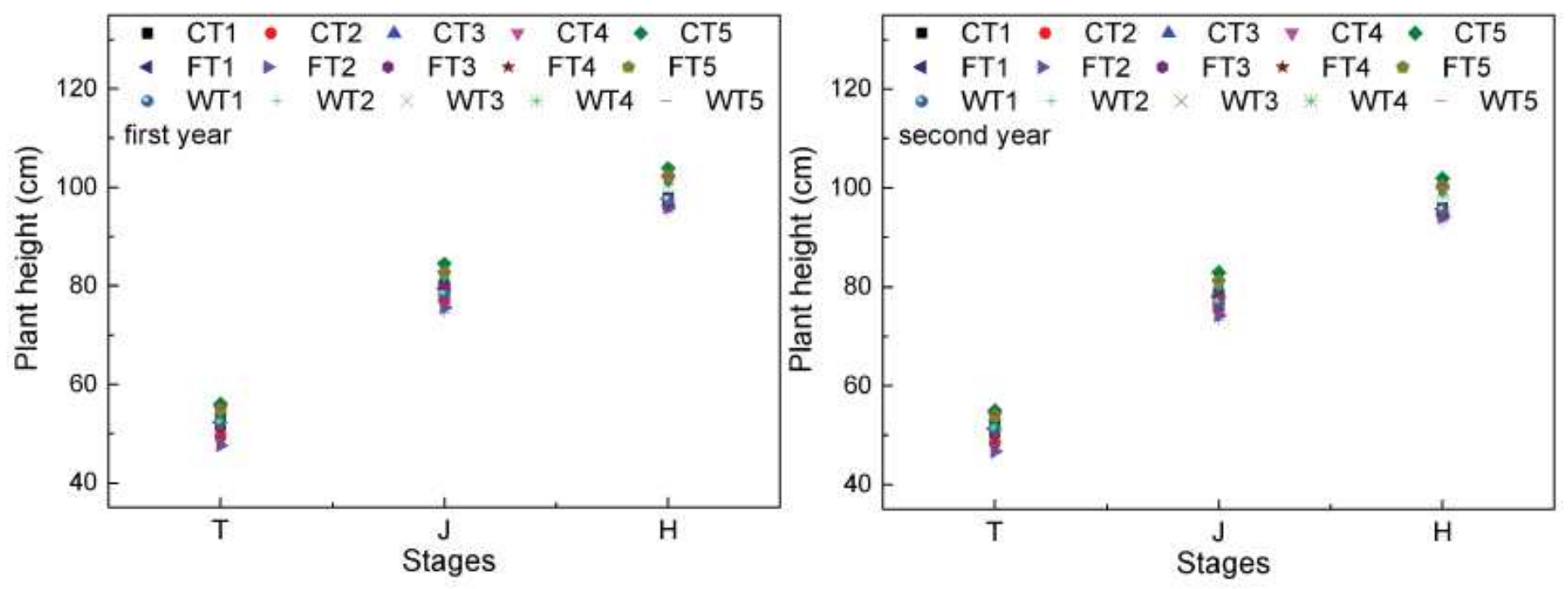

Figure 5

The plant height in different treatments Note: $\mathrm{C}$ represents control irrigation; $\mathrm{W}$ represents wet irrigation; $\mathrm{F}$ represents flood irrigation; T1,T2,T3,T4,T5 represents five fertilization treatments. T, J, H represents tillering, jointing, heading, respectively. 

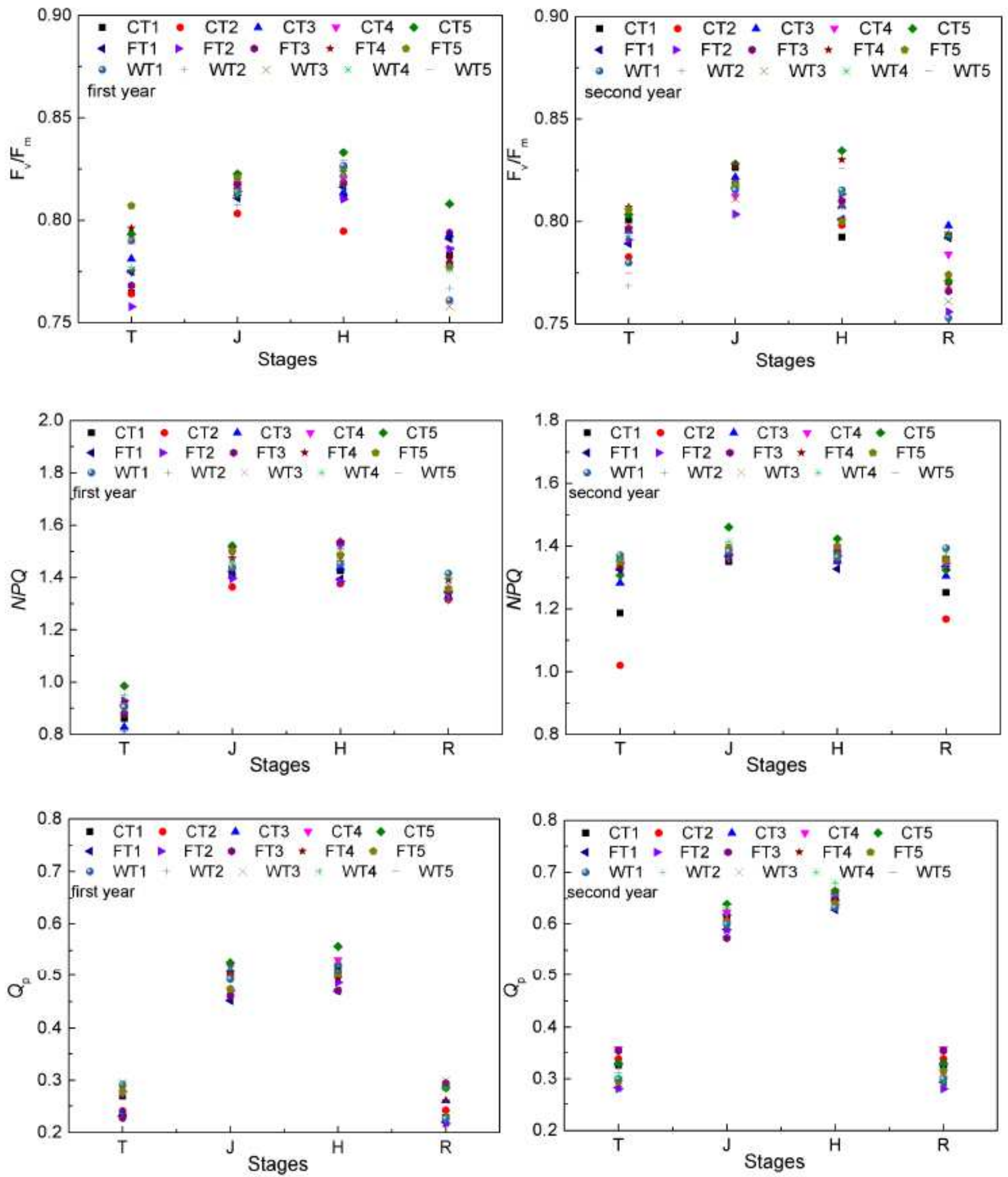

\section{Figure 6}

The fluorescence indexes in different treatments Note: $\mathrm{C}$ represents control irrigation; $\mathrm{W}$ represents wet irrigation; $F$ represents flood irrigation; $T 1, T 2, T 3, T 4, T 5$ represents five fertilization treatments. $T, J, H, R$, represents tillering, jointing, heading and ripening, respectively. 

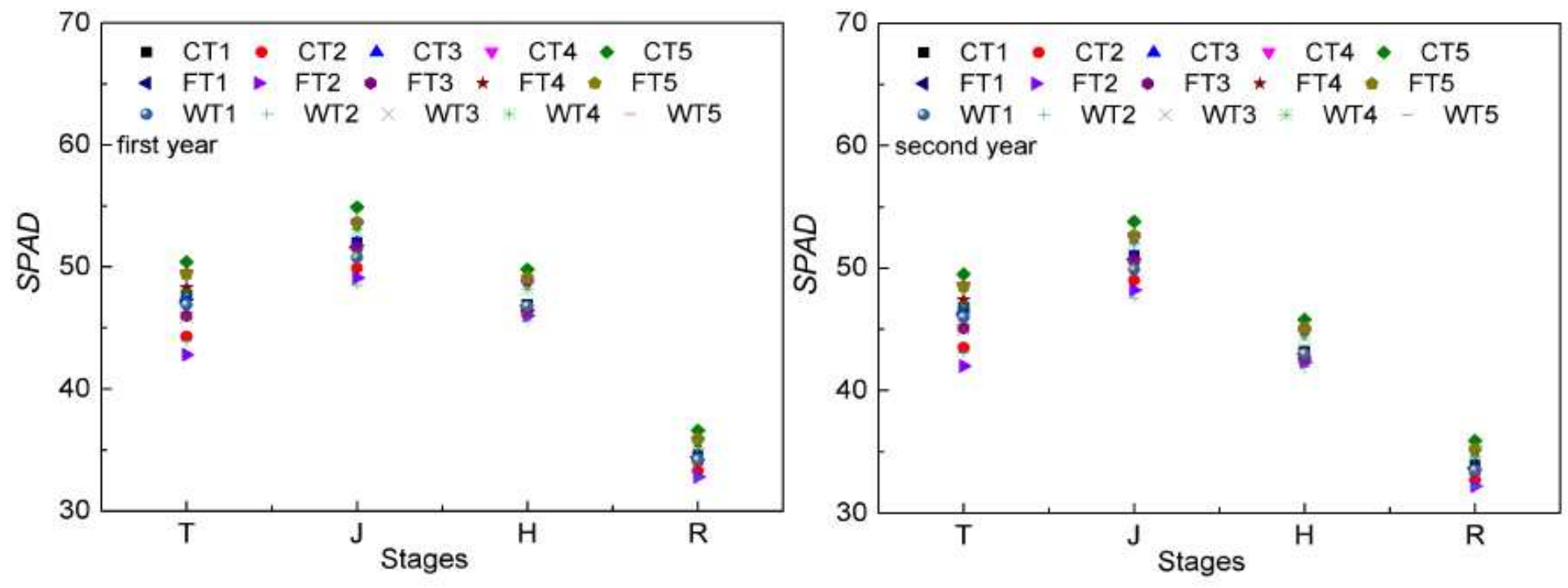

Figure 7

The SPAD in different treatments Note: $\mathrm{C}$ represents control irrigation; $\mathrm{W}$ represents wet irrigation; $\mathrm{F}$ represents flood irrigation; T1,T2,T3,T4,T5 represents five fertilization treatments. $T, J, H, R$, represents tillering, jointing, heading and ripening, respectively. 

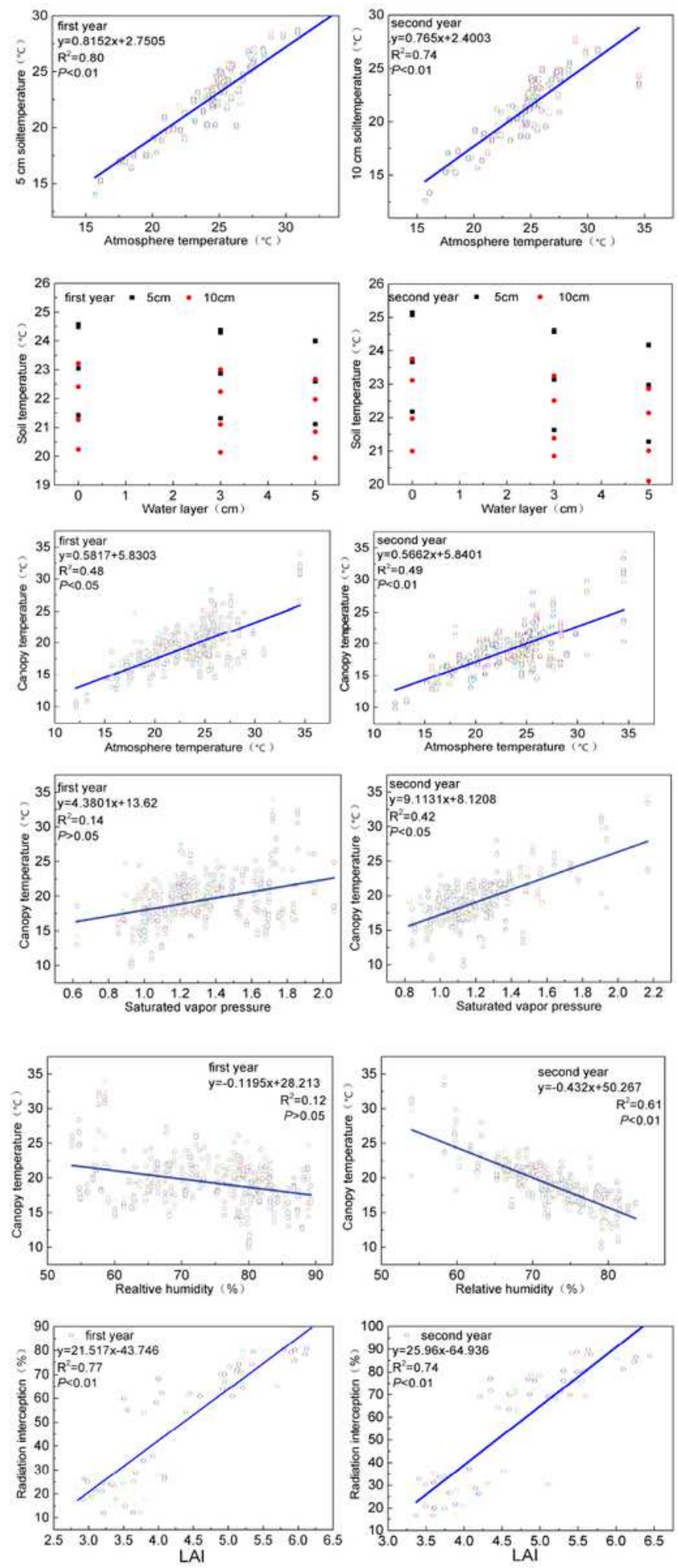

Figure 8

Analysis of influencing factors Note: LAl represents the leaf index 